\title{
PROPOSTA DE UMA METODOLOGIA JURÍDICA PARA O ESTUDO DA LIBERDADE RELIGIOSA NA RELAÇÃO LABORAL
}

\section{PROPOSAL FOR A LEGAL METHODOLOGY FOR THE STUDY OF RELIGIOUS FREEDOM IN LABORAL RELATIONSHIP}

\author{
Susana Sousa Machado ${ }^{1}$
}

\section{RESUMO}

Neste artigo, partimos do reconhecimento da composição pluralista da sociedade subjacente ao mundo contemporâneo, em que a presença do fator religioso no mundo do emprego não pode ser ignorada. Esta questão coloca desafios em relação à proteção da liberdade religiosa dentro do contexto das relações de trabalho. Atualmente, as sociedades estão cada vez mais heterogéneas, mais diversificadas e a mobilidade humana está a crescer constantemente. Todas essas questões têm consequências no mundo do trabalho, pois as empresas são um palco para a interculturalidade e, portanto, a questão das crenças religiosas dos trabalhadores no local de trabalho merece ser estudada.

Partindo destas premissas, o presente artigo tem por objetivo apresentar uma proposta de metodologia jurídica para o estudo da liberdade religiosa na relação laboral. No artigo defendese que a questão será metodologicamente melhor analisada se forem atendidas particularidades dogmáticas do direito do trabalho que extravasam a mera consideração da liberdade religiosa à sombra da igualdade. O modelo proposto para o estudo da questão enunciada contempla a contextualização do problema, a definição do objeto de estudo, a metodologia e os eixos relativos aos problemas concretos a resolver.

Palavras-chave: religião, liberdade religiosa, direito do trabalho

\begin{abstract}
In this paper we start from the acknowledgement of the pluralistic composition of the society underlying the contemporary world in which the presence of the religious factor in the world of employment cannot be ignored. This issue places subtle challenges regarding the protection of religious freedom within the context of working relationships. Nowadays societies are becoming increasingly heterogeneous, more diverse, and human mobility is persistently growing. All these issues have consequences in the world of work as the businesses can truly be a stage for interculturality and the place of the employee's religious beliefs deserves, therefore, to be studied.

Based on these premises, this article aims to present a proposal of legal methodology for the study of religious freedom in the labor relationship. The article argues that the issue will be methodologically better analyzed given the main dogmatic particularities of the labour law that

\footnotetext{
${ }^{1}$ Licenciada e Mestre em Direito pela Faculdade de Direito da Universidade de Coimbra e Doutora em Direito do Trabalho pela Universidade de Santiago de Compostela. Professora Adjunta na Escola Superior de Tecnologia e Gestão do Politécnico do Porto. Instituto Politécnico do Porto - Portugal. E-mail: scm@estg.ipp.pt
} 
go beyond the mere consideration of religious freedom in the shadow of equality. The proposed model for the study of the enunciated question contemplates the contextualization of the problem, the definition of the object of study, the methodology and the axes related to the concrete problems to be solved.

Keywords: religion, freedom of religion, labour law

\section{INTRODUÇÃO}

As questões respeitantes ao impacto das crenças religiosas na relação laboral representam, nos nossos dias, um problema bastante evidente, prevendo-se que assuma cada vez mais relevância nas sociedades contemporâneas (MACHADO, 2018, p.13-14).

Isto resulta, por um lado, do fenómeno da globalização e, por outro, dos movimentos migratórios que potenciam o multiculturalismo e os conflitos que daí decorrem. A homogeneidade religiosa já não é o paradigma e, mesmo em sociedades onde a diversidade religiosa é escassa, surgem de forma crescente conflitos.

A Europa das últimas décadas tem-se transformado progressivamente numa sociedade multicultural, levando atrás de si diversos problemas relacionados com os diferentes hábitos e costumes com os quais a sociedade e o direito se têm de confrontar. No entanto, a diversidade cultural deve ser encarada como um bem jurídico protegido. Os elementos que dão corpo à identidade cultural, dando forma à personalidade humana, abrangem as mais diversas áreas, designadamente a arte, as tradições, os valores, o relacionamento social e as crenças (NÚÑ̃Z GONZÁLEZ, 2009, p. 21).

A tolerância religiosa já não é suficiente para garantir a igualdade. Perante uma sociedade multicultural onde estão presentes minorias, deve ser seguida uma ação positiva de acomodação das crenças religiosas. De facto, a falência do modelo multiculturalista de tolerância generalizado na década de 70 do século passado em vários ordenamentos ocidentais é já apontada pela doutrina (MACLURE e BOUCHER, 2015, p. 343-344). Tendo em conta a relevância crescente do impacto das crenças religiosas na vida em sociedade é evidente que uma das áreas onde os problemas são mais delicados é no domínio das relações laborais.

Perante a indiscutível premência do estudo do impacto de liberdade religiosa na relação laboral, apontamos uma proposta de modelo de metodologia jurídica para um posterior estudo do problema. Para o efeito, é contextualizado o problema, definido o objeto de estudo, apontada a metodologia e elencadas as questões concretas a resolver. 


\section{CONTEXTUALIZAÇÃO: UMA SOCIEDADE MULTICULTURAL}

Os ordenamentos jurídicos desenhados à luz de uma certa homogeneidade cultural deparam-se com um problema resultante da falta de maturação das tradições de outras culturas. Trata-se de sociedades em que os valores fundamentais surgiram e cresceram em harmonia com a cultura judaico-cristã.

Perante o incremento da multiculturalidade num mundo cada vez mais global em virtude do crescimento da circulação de pessoas, a convivência entre indivíduos com diferentes crenças religiosas tornou-se uma realidade presente nas sociedades atuais. Esta diversidade religiosa demanda novas soluções já que certas práticas religiosas podem pôr em causa convenções socialmente estáveis para a maioria dos cidadãos.

Vai-se afirmando o crescimento de uma sociedade plural em que a gestão da diversidade constitui um dos desafios sociais mais prementes do século XXI. As crenças religiosas escapam ao anonimato, tornam-se visíveis, suscitam conflitos; vive-se no dilema entre assegurar a liberdade religiosa sem obstáculos e, ao mesmo tempo, proteger a autonomia da consciência (FORTIER, 2009, p. 147).

De modo inevitável, o mundo laboral tornou-se numa amostra do mundo global e passou, também ele, a ser um terreno de manifestação religiosa, mas, ao mesmo tempo, um campo de tensão perante o pluralismo religioso cada vez mais presente nas sociedades ocidentais. E a tendência das interações num mundo globalizado indiciam que o fenómeno da pluralidade religiosa continuará a crescer o que sustenta o interesse de desenvolver posições jurídicas sobre a temática.

Tendo, então, em conta a relevância e a atualidade do tema, no contexto de um pluralismo religioso e ideológico crescente, pode afirmar-se que as relações laborais são um campo especialmente fértil para a ocorrência de conflitos relacionados com a manifestação da liberdade religiosa. Esta parece ser uma afirmação facilmente inteligível já que os indivíduos despendem grande parte do seu tempo a trabalhar de modo a assegurar o sustento próprio e o da família. Como refere Machado (1996, p. 264) os direitos, liberdades e garantias dos trabalhadores são "tributários de uma consciencialização progressiva, em boa parte da responsabilidade dos movimentos socialistas e sociais democratas, da posição especial de vulnerabilidade em que os indivíduos se encontram quando dependem apenas, para a sua subsistência, da alienação da força do seu trabalho a uma empresa privada". 
Por outo lado, as crenças religiosas têm a capacidade de se manifestarem para além da vida privada, já que não pertencem exclusivamente ao plano íntimo e, dessa forma, tornam-se aptas a moldar o comportamento do cidadão-crente nas diversas dimensões da sua vida, incluindo toda a atuação quotidiana com especial destaque para o tempo e o espaço de desenvolvimento da atividade laboral onde surge, então, o cidadão-crente-trabalhador.

O trabalhador hodierno nega-se a viver teatralmente dividido entre duas dimensões e a ter que fazer escolhas nesse sentido, ou seja, recusa-se a abandonar as suas convicções religiosas no tempo e no local de trabalho. A problematicidade da questão situa-se na coincidência de tempo e lugar entre o homo religiosus e o homo laborans personificada no mesmo indivíduo.

A pessoa do trabalhador transporta consigo, tanto no momento de celebração do contrato de trabalho como na execução do mesmo, um universo axiológico que ele próprio elegeu para formarem a sua identidade, o que inclui os valores que derivam do credo religioso que professa. Por isso, o trabalhador deve dispor das garantias de defesa dos direitos fundamentais concedidos pelo ordenamento jurídico e que se concretiza, nomeadamente na expectativa de não intromissão ou ingerência por parte do empregador na esfera da sua liberdade, e portanto, na expectativa de não sofrer qualquer dano ou prejuízo de caráter laboral como resultado das suas convicções religiosas e da exteriorização dessas convicções (VALDÉS DAL-RÉ, 2006, p. 588).

O facto de o cidadão-crente-trabalhador se fazer sempre acompanhar por uma certa cosmovisão decorrente da sua crença religiosa, isto porque "a conduta humana não é materialmente cindível da pessoa do seu autor" (CORDEIRO, 1982, p. 135), tem particular relevância no domínio da relação laboral onde existe um desequilíbrio material entre as partes o qual se apresenta como reduto da dogmática laboral. Por isso, todo o entendimento subjacente ao equilíbrio de posições jurídicas deve levar em consideração a necessidade de proteção da parte mais fraca como forma de restabelecer a igualdade ${ }^{2}$. Por outro lado, deve atender-se ao facto de a relação laboral também ser caraterizada pelo elemento da subordinação jurídica de um sujeito a outro.

\footnotetext{
${ }^{2}$ Relativamente à dogmática laboral Cordeiro $(1982$, p.146) escreve que "a necessidade de protecção da parte fraca, a busca de soluções materiais e não apenas formais, a limitação da autonomia privada sempre que essa conduzisse a soluções inconvenientes ou pervertidas, a intervenção de entidades terceiras como forma de acautelar o interesse comum e, finalmente, o reconhecimento de um nível jurídico colectivo como forma de repor a autonomia e a igualdade perturbadas nas situação individual".
} 
A manifestação ou a exteriorização ${ }^{3}$ de opções religiosas no tempo e no local de trabalho pode esbarrar com algumas formas de intolerância o que impede uma convivência isenta conflitos entre todos os sujeitos da relação laboral. Estes conflitos que podem afetar com alguma intensidade certas premissas da relação laboral, e até mesmo atingir o exercício da atividade empresarial, decorrem na grande maioria dos casos da oposição do empregador à manifestação da crença religiosa dos seus trabalhadores.

O exercício da liberdade religiosa das minorias, mas não só, constitui um dos pontos de discussão mais relevantes com que se enfrentam as sociedades ocidentais numa tendência marcada pelo fenómeno da integração dentro de uma dinâmica globalizadora (CAÑAMARES ARRIBAS, 2007, p. 527). De facto existem cada vez mais conflitos no seio das relações laborais provocados pela necessidade de os trabalhadores, a maioria das vezes pertencentes a minorias religiosas, exercerem certas práticas religiosas ${ }^{4}$. Nestes casos, a conduta do trabalhador gera um universo de tensões quanto aos limites razoáveis do exercício do direito à liberdade religiosa.

Os conflitos que encontram a sua génese no fator religioso e que podem ocorrer no âmbito da relação laboral são bastantes. A tentativa de resolvê-los esbarra as mais das vezes em entendimentos restritivos do direito à liberdade religiosa e, por vezes, também, numa compreensão que sobrevaloriza os poderes do empregador e a liberdade de empresa. Estas dificuldades podem, porém, ser tendencialmente ultrapassadas através da acomodação razoável das práticas religiosamente orientadas no domínio da relação laboral.

Em termos gerais, pode afirmar-se que a integração exige acomodação (VICKERS, 2014, p. 602). Esta forma de superação dos conflitos funciona como um catalisador à capacidade de trabalhadores e empregadores aceitarem o pluralismo e atuarem como agentes do princípio da tolerância. É, porém, um desafio constante a capacidade de cada um se moldar a um ambiente multicultural mas que se torna essencial num Estado de direito governado pela democracia.

Toda esta ordem de ideias exige um balanceamento das posições jurídicas em colisão: o direito fundamental à liberdade religiosa do trabalhador e a liberdade de empresa do empregador. Advirta-se, ademais, que em alguns casos, embora de menor representatividade,

\footnotetext{
${ }^{3}$ Tal como refere Hambler (2014, p. 3), o Tribunal Europeu dos Direitos do Homem (TEDH) prefere utilizar o termo "manifestação" (manifestation) apesar de ser um conceito mais restrito do que o de "expressão" (expression).

${ }^{4}$ Para uma exposição sobre os conflitos entre diversas liberdades pode ser consultado Montero (2011, p. 6-7).
} 
também pode existir colisão entre a liberdade religiosa do trabalhador e posições assumidas por terceiros, nomeadamente colegas e clientes, que acabam por ter reflexos na relação laboral.

A atuação em conformidade com as crenças religiosas no local e no tempo de trabalho revela-se, portanto, uma temática envolta numa inexorável complexidade que apela à intervenção de múltiplos princípio basilares de uma ordem jurídica assente na democracia. $\mathrm{Na}$ confluência de todas estas ideias encontramos posições sustentadas em valores universais como o princípio da igualdade, a liberdade de expressão, a liberdade de consciência, a autodeterminação, o livre desenvolvimento da personalidade, a dignidade da pessoa humana, a neutralidade, a laicidade. Mas quando toca a colisões que envolvem as relações laborais surgem posições jurídicas consubstanciadas, também, nos limites aos poderes do empregador, no direito à liberdade de empresa, no direito à desobediência legítima perante ordens contrárias aos direitos e garantias do trabalhador, no princípio do pacta sunt servanda, entre outros.

Desta amálgama de ideias resultará uma compreensão da liberdade religiosa tendo como referência um modelo de tolerância suportado na ideia de que, em regra, o trabalhador não pode ser privado da manifestação das suas convicções religiosas no tempo e no local de trabalho, salvo em situações concretas devidamente justificadas e normalmente associadas à liberdade de empresa do empregador. Este modelo de tolerância no tratamento do fenómeno religioso terá como corolário o reconhecimento do dever do empregador de acomodação das convicções religiosas dos trabalhadores sempre que isso não afete de forma desproporcional outros bens e interesses com igual dignidade constitucional (JÚNIOR, 2013, p. 3).

Apesar de ser claro que no domínio laboral nenhum trabalhador pode ser discriminado em razão da religião não se conseguem evitar certas questões inquietantes: "Como integrar as práticas religiosas do trabalho no funcionamento da empresa sem afectar a organização produtiva?”, "Onde é que está o limite entre a proibição e a tolerância?”. A resposta a estas questões pode variar em função de diferentes contextos, já que a heterogeneidade da visão religiosa do mundo pode colher diferentes sensibilidades.

A dificuldade prática de conciliação entre exigências aparentemente opostas que, ou se situam na zona da vida privada ou pertencem ao mundo do trabalho, pode ser ilustrada em concreto: "Que atitude tomar perante uma mulher que se apresenta de véu islâmico numa entrevista para um emprego?”, “O que fazer perante a exigência do trabalhador que reclama tempo de espaço para oração na empresa?”, “Que atitude tomar relativamente a um trabalhador que pretende ausentar-se por motivos de festividade religiosa?", "Como organizar o serviço de refeições quando certos trabalhadores só comem kosher ou halal?”. 
Assim, surgem novos desafios como consequência da diversidade cultural e religiosa. Atualmente, e muito devido à crescente mobilidade de cidadãos com convicções religiosas diversas, coloca-se a questão de saber como conciliar exigências da empresa e a liberdade religiosa dos trabalhadores numa sociedade plural quando a gestão da diversidade constitui um desafio emergente e uma aposta coletiva. A este respeito, o ordenamento jurídico deve estar preparado para acompanhar as alterações sociais e responder a esta evolução de modo afirmativo.

Tem-se verificado um interesse cada vez mais notório sobre a gestão da diversidade religiosa no âmbito laboral assumindo-se, ao mesmo tempo, como um propósito difícil de concretizar já que atender às exigências individuais, tomando em consideração a diversidade de crenças, pode pôr em causa a coesão social do coletivo na empresa ${ }^{5}$.

Quando se pensa numa gestão eficaz da diversidade religiosa dentro das empresas determina-se logo, à partida, que esta problemática é indissociável da discriminação direta ou indireta (LASSERRE, 2012, p. 1072). Mas mais importante é a questão de determinar se, nestes casos, deve prevalecer o direito a um tratamento diferente que corresponda a uma acomodação razoável sem que sejam afetados de modo desproporcional os direitos dos outros ${ }^{6}$.

Deste modo, o estudo do impacto da religião no domínio laboral é pertinente, atual e necessário de modo a prover instrumentos jurídicos adequados a regular as singularidades desta relação. De tal forma, que se permita o pleno exercício da liberdade religiosa sem vulnerar eventuais limites necessários para proteger outros bens e interesses de igual dignidade.

\section{OBJETO DE ESTUDO}

Partindo do reconhecimento da relevância e atualidade do pluralismo religioso e do aumento da litigância que se vai observando é percetível a relevância do estudo da temática da

\footnotetext{
${ }^{5}$ Sobre a gestão intercultural da empresa, GONZÁLEZ (2009, pp. 95-162).

${ }^{6}$ Convém sublinhar que, a este respeito, o direito da União Europeia apenas prevê um tratamento preferencial para as pessoas com deficiência, através de consagração de uma obrigação de acomodação razoável a cargo do empregador. O art. 5..$^{\circ}$ da Diretiva 2000/78/CE do Conselho, de 27 de novembro de 2000, que estabelece um quadro geral de igualdade de tratamento no emprego e na atividade profissional, sob a epígrafe "Adaptações razoáveis para as pessoas deficientes" determina que "para garantir o respeito do princípio da igualdade de tratamento relativamente às pessoas deficientes, são previstas adaptações razoáveis. Isto quer dizer que a entidade patronal toma, para o efeito, as medidas adequadas, em função das necessidades numa situação concreta, para que uma pessoa deficiente tenha acesso a um emprego, o possa exercer ou nele progredir, ou para que lhe seja ministrada formação, excepto se essas medidas implicarem encargos desproporcionados para a entidade patronal".
} 
relação entre a liberdade religiosa e a relação laboral. Efetivamente, justifica-se uma investigação que enfrente alguns dos desafios mais importantes e delicados que se colocam no exercício do direito à liberdade religiosa no seio da relação laboral.

Este exercício não se deve limitar, como vem sendo habitual em estudos jurídicos nesta matéria, a uma dimensão negativa que procura encontrar mecanismos de proteção contra intromissões do empregador no núcleo da liberdade religiosa do trabalhador. No mundo contemporâneo exige-se mais. Exige-se uma valorização da dimensão positiva de natureza prestacional (MACHADO, 2006, p. 110) que cuida de propiciar a exteriorização das convicções religiosas mesmo no domínio da relação laboral o que se revela essencial num Estado de direito democrático.

Nesse sentido, a nossa proposta não se centra tanto na análise do problema com enfoque na proibição de discriminação em razão das convicções religiosas, vertente já bastante aprimorada pela doutrina e pela jurisprudência, mas antes na prestação positiva de meios indispensáveis à realização do exercício da liberdade religiosa. Partimos assim da teoria já acolhida pela jurisprudência de que da tutela da liberdade de religião "decorrem os princípios de tolerância e de acomodação dos direitos derivados do exercício da religião no âmbito social como vetores do próprio programa normativo constitucional, que não se limita à afirmação de que o reconhecimento da liberdade religiosa no mundo laboral se efetua tão só através do princípio da igualdade e não discriminação"7.

De modo a tornar mais inteligível o âmbito do objeto de estudo, a discussão deve centrar-se nas implicações valorativas e principiais, e na análise das refrações, da liberdade religiosa nas relações laborais outorgadas com empregadores ideologicamente neutros e do setor privado. Ou seja, segundo a nossa proposta metodológica, o estudo deve centrar-se nas relações jurídicas relacionadas com a prestação de trabalho por conta de outrem no setor privado e em organizações ideologicamente neutras. Desta forma, é nossa pretensão esclarecer que a proposta de metodologia de estudo é delimitada por três pilares: trabalho subordinado, setor privado e empregadores ideologicamente neutros.

Em primeiro lugar, destacamos que a realidade juslaboral a incluir no objeto de estudo cuida do trabalho subordinado por conta de outrem. Esta opção não se prende com qualquer tentativa de desconsiderar realidades mais obscuras e, logo, mais penosas de prestação da atividade laboral mas tão só com uma opção metodológica. Para efeitos de delimitação do

\footnotetext{
${ }^{7}$ Acórdão do Tribunal Constitucional n. ${ }^{\circ}$ 544/2014, publicado no Diário da República n. ${ }^{\circ}$ 183/2014, Série II de 23.09.2014.
} 
âmbito não devem ser incluídas no estudo todas as modalidades de exercício de uma atividade produtiva mas apenas parte delas já que as relações laborais da nossa proposta metodológica são de trabalho subordinado, dependente e por conta alheia. Fernandes (2014, p. 16), referindose ao objeto do Direito do Trabalho, esclarece que este regula "as relações jurídico-privadas de trabalho livre, remunerado e subordinado". E, dessa forma, identifica como núcleo essencial o "trabalho subordinado, dependente, por conta alheia" mas acrescenta que "o Direito do Trabalho não cria este modelo de relação de trabalho: limita-se a recolhê-lo da experiência social, reconhecendo-o e revestindo-o de um certo tratamento normativo. A dependência ou subordinação que carateriza esse modelo não é uma imposição legal, é um dado da realidade".

Como segundo momento de delimitação, destacamos uma análise centrada nos aspetos mais significativos que caracterizam os conflitos sobre liberdade religiosa que surgem no âmbito de empregadores ou, mais concretamente, de empresas neutras, ou seja, no âmbito das organizações de trabalho, que correspondem à imensa maioria e que não têm a etiqueta de empresa de tendência (VALDÉS DAL-RÉ , 2006, p. 589). O conceito de empresa ideologicamente neutra aparece por contraposição ao conceito de empresa ideológica ou de tendência ${ }^{8}$. Devemos partir do princípio de que, em regra, todas as empresas são ideologicamente neutras porque não promovem uma concreta opção ideológica quer seja política ou religiosa ${ }^{9}$. Não têm como objetivo específico a defesa de uma certa ideologia e nem é em função dela que exercem a sua atividade.

Desta forma, a análise proposta circunscreve-se às relações laborais que surgem no domínio de empresas cujo fim principal seja o lucro, aquelas que se limitam a funcionar à luz da liberdade de iniciativa económica privada que se traduz na liberdade de iniciativa e de organização empresarial $^{10}$. No entanto, não se pode afirmar que a prossecução do lucro serve por si só para enquadrar o conceito de empresa ideologicamente neutra. Se bem que é verdade que não são organizações de tendência aquelas que têm como finalidade principal o lucro, nem

\footnotetext{
${ }^{8}$ Para uma melhor compreensão das organizações de tendência e a sua articulação com os direitos fundamentais, TOVAR (1992, p. 77-94 e 1980, p. 269 a 306).

${ }^{9}$ RIVERO (1991, p.191) põe em causa que se possa admitir a existência de empresas ideologicamente neutras já que os aparelhos hierárquicos e organizativos da empresa são, por si só, ideológicos, considerando, portanto, que em certo sentido toda a empresa é ideológica. Cremos que esta posição é algo restritiva porque a existência do elemento de "tendência" da organização é bastante evidente em alguns casos e inexistente em outros.

${ }^{10}$ Neste sentido pronunciou-se, a contrario sensu, o Tribunal Constitucional espanhol, no contexto da criação de centros privados de ensino, ao considerar que a organização cujo fim principal seja o lucro e que apenas se limite a exercer a liberdade de empresa prevista no art. $38^{\circ}$ da Constituição não entra no conceito de empresa de tendência (Sentença 5/81, de 13 de fevereiro, disponível em www.tribunalconstitucional.es).
} 
sempre corresponde à verdade a afirmação contrária, ou seja, onde não houver lucro há uma organização de tendência (RIVERO, 1991, p. 191).

Assim, o caminho mais seguro para caraterizar as empresas ideologicamente neutras é aquele que adota um conceito a contrario relativamente a empresas de tendência. Um pouco por toda a europa a doutrina inspirou-se no conceito alemão de "Tendenzbetrieb" para criar a sua própria noção de "empresa de tendência", "empresa de tendencia", "entreprise de tendance" ou "impresa di tendenza" nos diferentes ordenamentos jurídicos. Em termos genéricos pode dizer-se que a celebração de um contrato de trabalho com uma empresa destas pode levar o trabalhador a ter que cumprir certos deveres específicos de modo a permitir que essa empresa alcance o seu propósito correspondente a uma certa ideologia. Desta forma, não deve ser incluído no âmbito do estudo as organizações de tendência religiosa, as instituições em que o empregador é uma instituição religiosa ou prossegue uma certa orientação religiosa mas também quando se trata de uma organização ou empresa com certo objetivo ideológico. Como refere SAVATIER (1987, p. 377), o que está em causa não é a “comunhão de fé” mas a "comunhão de pensamento" que o empregador pode exigir de certos trabalhadores.

Como tal, o objeto da nossa proposta cuida do empregador enquanto ente neutro em matéria religiosa, se bem que a pessoa do empregador e todos os trabalhadores podem ter as suas próprias convicções religiosas individuais sem que isso interfira na qualificação de empregador ou empresa neutra. Por isso, a nossa perspetiva, certamente a mais complexa e extensa mas menos conhecida e estudada, é a que observa o fator religioso no contexto de uma empresa ideologicamente neutra e em que o trabalhador tem as suas próprias convicções religiosas. Neste contexto, não cabe apreciar a influência do fator religioso na relação laboral quando esta se desenvolve no contexto de uma empresa ideológica ou de tendência.

Esse alinhamento do âmbito da nossa análise deveu-se à situação de nas organizações de tendência estar em causa uma base factual e valorativa distinta relativamente ao que ocorre nas empresas neutras o que pode conduzir a soluções diferenciadas ${ }^{11}$. Um trabalhador que

\footnotetext{
${ }^{11}$ Veja-se o seguinte exemplo no contexto norte americano. A utilização de símbolos religiosos distintos daqueles prescritos pela confissão religiosa que assume o papel de empregador leva a um conflito entre a liberdade religiosa do trabalhador e a do empregador o qual tem os seus próprios símbolos religiosos. Um exemplo de como a jurisprudência americana tem tratado o problema é a decisão Equal Employment Opportunity Commission v. Presbyterian Ministries, Inc. (788 F. Supp. 1154, (1992), que diz respeito a Jacqueline Brooks que trabalhava como rececionista numa casa para idosos, gerida por uma confissão religiosa. Pouco depois de ter iniciado funções esta trabalhadora apresentou-se de véu islâmico invocando que a sua religião e o seu marido o exigiam. O empregador explicou a essa trabalhadora que tal símbolo religioso era contrário aos princípios cristãos pelos quais se regia a instituição onde trabalhava. E, portanto, a trabalhadora deveria retirar o véu ou abandonar o trabalho. Em tribunal foi discutida a discriminação em função da religião e o facto de todos os trabalhadores conhecerem e apoiarem o manual interno do centro. Apesar de o trabalho de rececionista ser um posto secular isso não significa
} 
exerça a sua atividade numa empresa cuja atividade tem um propósito religioso pode ver a sua liberdade condicionada até um certo limite. Em princípio, o empregador não pode sancionar um trabalhador por factos relacionados com a sua vida pessoal que são exteriores à relação de trabalho. No entanto, nas empresas de tendência o empregador pode, verificados certos requisitos, valorar tais factos ${ }^{12}$.

Por todas estas especificidades o objeto centra-se em trabalhadores que exercem funções para uma entidade empregadora descomprometida com qualquer ideologia, máxime religiosa ${ }^{13}$. Por fim, clarificamos que o âmbito da nossa proposta de estudo se foca nas relações laborais do setor privado. Assim, a investigação deve abranger a dinâmica das relações laborais inter privatos deixando de fora do perímetro de tratamento dogmático o trabalho em funções

que não esteja imbuído da missão cristã do centro, até porque a função de rececionista é importante para transmitir a primeira impressão da instituição. Assim, determinou que no caso não foi violada a Free Exercise Clause porque o trabalhador é livre de exercer a sua religião mas não pode impedir o exercício da liberdade religiosa do empregador. Neste caso, ficou claro que o ambiente cristão a manter era fundamental para não ser acionada a exceção contemplada na secção 702 à Establishment Clause que permite aos trabalhadores usarem símbolos religiosos e fazer proselitismo, e que por outro lado, seria uma intromissão nos assuntos internos afetando o ambiente cristão que se quer criar no centro. No que diz respeito à acomodação, o tribunal considerou que procurar interferir na capacidade de direção do centro de idosos de acordo com uma imagem e um ambiente cristão ultrapassaria a intromissão mínima o que representaria mais do que o custo mínimo em acomodar as crenças do trabalhador.

12 Já em 1986, a jurisprudência da Cour de Cassation se orientou no sentido de que as normas do Code du Travail que determinam que nenhum trabalhador pode ser punido ou despedido pelas suas crenças religiosas, são sucetíveis de não aplicação quando este foi admitido para desempenhar certas funções que impliquem a partilha de certas crenças do seu empregador (Cour de Cassation, Chambre sociale, 20 de novembro de 1986, Droit Social, n. ${ }^{\circ}$ 4, $\mathrm{p}$. 379). Pode ler-se na decisão que a fórmula em causa se aplica aos casos em que o trabalhador "a été engagé pour accomplir une tâche impliquant qu'il soit en communion de pensée ou de foi avec son employeur”. No entanto, o comprometimento do trabalhador com certos ideais não se pode aplicar com o mesmo grau de intensidade a todos os trabalhadores já nem todas as tarefas implicam a mesma comunhão de pensamento com a empresa. Assim sendo, uma instituição religiosa pode admitir ao seu serviço um trabalhador de uma outra confissão religiosa desde que este respeite a "obrigação de reserva". Esta expressão foi utilizada por JEAN SAVATIER (1987, p. 377) a propósito da Decisão do Conselho Constitucional francês, de 23 de novembro de 1977, relativo a um professor de matemática não crente que por trabalhar num estabelecimento de ensino católico deveria respeitar, através do seu comportamento e do modo de se expressar, as características próprias do estabelecimento, sem que isso implique uma plena comunhão de fé com o seu empregador. Numa empresa de tendência a orientação religiosa pode não fazer parte do acervo contratual de todos os trabalhadores. No entanto, para certo tipo de funções a religião pode fazer parte do contrato e, nesses casos, o empregador pode ter em consideração as crenças religiosas do trabalhador ou a sua atitude perante a religião. Note-se que não poderá estar em causa uma atitude discriminatória do empregador perante as crenças religiosas do trabalhador, já que o empregador apenas pode atender aos factos que lhe causem um claro distúrbio dentro da empresa.

${ }^{13}$ Se bem que o elemento distintivo na resolução dos problemas não está tanto na qualificação do empregador mas nas funções efetivamente exercidas. Note-se, entre tantos outros, o certeiro comentário de REIS (2001, p. 110): "não nos restam, com efeito, dúvidas que o trabalhador (qualquer trabalhador) não deve obediência à sua entidade empregadora senão em função do que pelo tipo de funções que exerce está obrigado a fazer, donde haja que considerar as funções que o concreto trabalhador «afectado» exerce e determinar se devem qualificar-se como «de tendência», no sentido de tarefas intrinsecamente ligadas à tendência ou ideologia da organização, ou antes como «neutras», "descomprometidas» ou "distantes» relativamente à tendência ou ideologia professada, estas submetidas, sem alterações, ao regime geral que proíbe o despedimento por motivos políticos ou ideológicos." 
públicas. Não obstante, cabe referir que em situações pontuais, pela relevância das considerações teoréticas e dogmáticas, deve ser feito o paralelismo com casos em que se expõe a problemática da liberdade religiosa no contexto de relações laborais no setor público suscetíveis de extrapolação valorativa e principal para o âmbito concreto da investigação.

Também os trabalhadores do setor público, como qualquer outro cidadão, podem exercer o seu direito à liberdade religiosa ${ }^{14}$. No entanto, tal como ocorre com os demais direitos fundamentais esse exercício pode ser modulado em função da tarefa que desempenhe o trabalhador. Estas limitações devem ser estabelecidas por lei e ser determinadas em função das necessidades do serviço público das exigências de imparcialidade, eficácia e hierarquia e de outros princípios constitucionais (JOVER, 2008, p. 805). Todavia, o modo como estes trabalhadores são afetados pode ser diferente em função das tarefas que desempenham e do cargo que ocupam. Normalmente, o interesse público é invocado nas relações de trabalho com o Estado como forma de assegurar o princípio da neutralidade o qual justifica, em regra, limitações ao exercício da liberdade religiosa ${ }^{15}$. Nestes casos, coloca-se um conflito entre a liberdade religiosa do trabalhador e o interesse do Estado em garantir a neutralidade, o que pode exigir uma argumentação valorativa distinta relativamente ao setor privado. Como salienta JOVER (2005, p. 24), o entendimento sobre o termo neutralidade não é sempre o mesmo, bastando, para o efeito, comparar as distintas soluções que são dadas pelos diferentes países europeus para perceber que a neutralidade tem um alcance distinto conforme o contexto concreto.

Esta dicotomia é perfeitamente ilustrada nas palavras de MACHADO (2010, p. 7) quando escreve que a vitalidade do fenómeno religioso "coloca problemas importantes no tocante à presença da religião no local de trabalho, seja nas relações de emprego público, subordinadas a princípios constitucionais e à prossecução do interesse público, seja nas relações de emprego privado, em que prevalecem a liberdade contratual e a prossecução de interesses particulares".

Definido o âmbito das relações laborais objeto de estudo não se pode esquecer que a dialética emergente resulta do balanceamento entre, por um lado, a liberdade religiosa do trabalhador e, por outro, a liberdade de empresa. Assim, o tratamento da dinâmica do direito à

\footnotetext{
${ }^{14}$ Sobre as especificidades do exercício do direito à liberdade religiosa no contexto da relação laboral no setor público, BROWN (2007, pp. 665-682).

15 Em termos de litigância, as principais divergências surgem no momento de determinar se a utilização de símbolos religiosos é compatível com a neutralidade do exercício de funções públicas, nomeadamente na escola.
} 
liberdade religiosa no âmbito da relação laboral convoca uma abordagem da sua incidência no direito constitucional da liberdade de empresa. Daqui irradia o poder de direção do empregador e o correspondente dever de obediência do trabalhador a par com o ius resistentiae.

Neste contexto, deve ser analisada a liberdade de empresa, em diferentes dimensões, enquanto limitação específica do direito à liberdade religiosa no seio das relações laborais e a consequente ponderação de direitos e bens que esse exercício pode colocar no caso de se verificar uma colisão de direitos.

$\mathrm{Na}$ medida em que a liberdade religiosa é multidimensional e propicia variadas abordagens devem identificar-se as suas principais refrações no domínio da relação laboral. Uma vez identificadas essas refrações, correspondentes a pontos de tensão concretos, é relevante densificar e problematizar conceitos associados ao direito à liberdade religiosa e, consequentemente, discutir as suas implicações valorativas no seio das relações laborais.

Ao longo deste percurso cumpre averiguar se é possível encontrar espaço para o dever de acomodação razoável da liberdade religiosa no domínio da relação laboral, tendo sempre presente os desafios que isso suscita.

\section{METODOLOGIA}

Sob o ponto de vista metodológico impõem-se algumas considerações para que a investigação proposta seja verdadeiramente apreendida tendo em conta a decisiva relevância da garantia da sua unidade sistemática.

Em primeiro lugar, destacamos que o trabalho a desenvolver se deve integrar no domínio da dogmática jurídica e, mais concretamente, transpondo ideias próprias dos direitos fundamentais para o domínio da relação laboral. É claro que uma leitura da liberdade religiosa e de todos os princípios que lhe estão associados não pode desconsiderar totalmente, tal como acontece em todas as áreas da dogmática jurídica, os contributos da filosofia, da sociologia ou das ciências religiosas mas sobretudo, da apreensão da realidade. Isto porque existe uma forte relação entre o plano jurídico e a praxis quotidiana correspondente à mundividência do cidadãotrabalhador-crente. Trata-se, portanto, de um trabalho de grande exigência que reclama um certo grau de densidade interdisciplinar ainda que, por vezes, com caráter meramente propedêutico.

Em segundo lugar, apesar da inquestionável análise do âmbito exclusivamente jurídico, tendo em conta as dimensões culturais mas sobretudo os problemas jurídico-dogmáticos vindos 
de enumerar, cabe notar que todas as afirmações expendidas ao longo da investigação devem ser absolutamente imparciais, numa perspetiva de sentimento de pertença a uma confissão religiosa. No entanto, seria utópico não sublinhar a idiossincrasia de uma concreta circunstância pessoal em que as posições assumidas, apesar de fundamentadas de modo a garantir a necessária imperturbabilidade científica, dificilmente se podem dissociar de uma auto-pré-compreensão do fenómeno religioso.

Em terceiro lugar, apesar das preocupações manifestadas quanto à resolução de conflitos, deve ser dada uma relevância primordial à análise casuística recorrendo à jurisprudência com origens diversas. Apesar do risco de fragmentação subjacente a uma análise casuística entendemos que esta é a melhor forma para conhecer a medida dos direitos e obrigações dos sujeitos intervenientes. Todavia, apesar de nos parecer justificado o recurso à análise casuística, a investigação não pode deixar de se referir a princípios gerais e a tentativas de construções amplas para a resolução de conflitos. Isto porque a solução não está exclusivamente reservada a uma resposta casuística na qual se afere a legitimidade de manifestação das crenças religiosas no tempo e no local de trabalho tendo em conta circunstâncias concretas multifacetadas. Defendemos que a mais valia a retirar das soluções (judiciais) casuísticas se reflete na possibilidade de realizar um projeto composto por soluções equilibradas para os problemas de colisão de direitos no tempo e no local de trabalho no domínio da manifestação da liberdade religiosa.

Em quarto lugar, destacamos o enriquecedor e inevitável recurso ao direito comparado enquanto principal fonte normativa e casuística. Esta compreensão global dos exemplos retirados do direito comparado torna-se determinante aquando do equacionamento da necessária hermenêutica jurídica tendente à busca de soluções. Todavia, emerge primordialmente, ainda que de forma mediata mas inevitável, a dogmática jurídica subjacente ao ordenamento jurídico interno. Para a concretização do objetivo proposto deve-se enriquecer a investigação com referências bibliográficas, normativas e jurisprudenciais oriundas de diversos ordenamentos jurídicos.

Neste tema em concreto, não seria metodologicamente correto apresentar soluções sem ter em conta a enriquecedora experiência jurídica de diversos ordenamentos daí a necessidade de uma forte preocupação quanto à ponderação casuística comparada. Deve ter-se também em conta a valiosa contribuição de órgãos supranacionais como o Tribunal de Justiça e o Tribunal Europeu dos Direitos do Homem. 
Em quinto lugar adverte-se que não deve existir uma pretensão de procurar traçar uma delimitação estanque quanto à disciplina jurídica que superintende o objeto da investigação. É, no entanto, seguro que se tem de partir da dogmática subjacente aos direitos fundamentais para caraterizar o direito à liberdade religiosa para chegar à realidade concreta do posicionamento da relação laboral. Assim, sem hipervalorizar o reconhecimento das posições jurídicas próprias do Direito do Trabalho, acreditamos no plus metodológico carreado pela dogmática juslaboral para uma compreensão articulada do direito fundamental à liberdade religiosa no concreto contexto das relações laborais e de toda a teia de refrações que daí derivam e que acabam por ser o objeto central da proposta de análise. Por isso, não é desejável ignorar que os direitos inerentes à pessoa humana não deixam de se manifestar e até assumir feições peculiares no domínio do Direito do Trabalho (CORDEIRO, 1982, p. 119-120).

Esta enfatização tem o propósito de evidenciar um Direito do Trabalho inclusivo e em permanente construção. Numa concetualização de iure constituendo pugnamos por um Direito do Trabalho apropriado às exigências do mundo contemporâneo, sem nunca vulnerar a sua intrínseca dogmática, o que se aplica naturalmente à dinâmica das convicções religiosas. $\mathrm{O}$ Direito do Trabalho terá à sua frente uma sociedade cada vez mais plural e tem que estar preparado para dar resposta aos conflitos que surgem em virtude da manifestação das convicções religiosas no contexto laboral.

A proposta metodológica apresentada deve contribuir nesse sentido, de tal modo que a litigância vindoura seja dirimida num quadro argumentativo mais sólido e menos hesitante sob a batuta de um Direito do Trabalho inclusivo que reconheça e aceite as diferentes manifestações religiosas de modo a permitir relações jurídico-laborais mais fraternas e solidárias.

\section{QUAESTIONEM SOLVERE}

O resultado final da investigação deve partir de uma abordagem geral mas articulada em termos dogmáticos de forma a seguir para uma perspetiva mais concreta onde são identificados os principais focos de conflito entre a liberdade religiosa e a relação laboral, sem nunca descurar a avaliação de ponto de conexão e de tensão com a consequente identificação de soluções.

Assim, para a concretização do objetivo proposto, a investigação deve ser dividida em cinco eixos: a liberdade religiosa num contexto laboral plural, o tempo de trabalho, a alimentação e a religião, os símbolos religiosos e a imagem e o proselitismo. Vejamos, por fim, 
o conteúdo da problematicidade inerente a cada um dos eixos que deve compor a investigação proposta.

\section{A LIBERDADE RELIGIOSA NUM CONTEXTO LABORAL PLURAL}

Este eixo tem por objetivo caraterizar o direito à liberdade religiosa e proceder à aplicação dos seus fundamentos no domínio da relação laboral como forma de perceber até onde é que o trabalhador pode legitimamente exercer o seu direito.

\section{O TEMPO DE TRABALHO}

Tendo em consideração que podem surgir verdadeiros conflitos de deveres entre preceitos religiosos e deveres típicos de uma relação laboral, devem ser analisadas questões especificas relativas à organização do tempo de trabalho. Por força das convicções religiosas do trabalhador, este pode ser confrontado com a necessidade de não trabalhar em dias que coincidam com festividades religiosas ou de usufruir de um determinado dia de descanso semanal ou, ainda, de efetuar certas pausas no tempo de trabalho para o cumprimento de determinados rituais.

Na medida em que a observância das festividades religiosas e do dia de descanso semanal varia consoante a confissão religiosa, o respeito pela liberdade religiosa do trabalhador pode colocar, neste aspeto particular, algumas dificuldades ao empregador em termos de gestão da unidade empresarial. Por isso, deve ser discutido o alcance do problema relativo ao respeito por certos períodos de não trabalho em função das convicções religiosas do trabalhador.

\section{A ALIMENTAÇÃO E A RELIGIÃO}

É necessário tratar da relação triangular entre alimentação, obrigações religiosas e trabalho. As diferentes religiões prescrevem proibições distintas quanto ao consumo de determinados alimentos que, em certos casos, até pode abranger apenas um certo período do ano. Podemos, portanto, encontrar casos em que existe, por um lado, uma proibição geral de consumir certos alimentos ou uma proibição restrita a um determinado lapso de tempo e, por outro lado, proibições respeitantes, não à ingestão do alimento propriamente dito, mas, à forma como é preparado ou conservado ou, ainda, proibições respeitantes ao mero contacto físico com 
certo produto alimentar. Transpondo estas prescrições para o local de trabalho, podemos afirmar que no contexto laboral a questão da alimentação pode colocar-se em três áreas distintas: fornecimento e preparação de refeições, observância de períodos de jejum e manipulação ou contacto com determinados produtos alimentares.

\section{OS SÍMBOLOS RELIGIOSOS E A IMAGEM}

As questões relativas ao uso de símbolos religiosos dão corpo a uma matéria sensível. Para a resolução deste tipo de conflitos deve partir-se da premissa de que o direito à liberdade religiosa possibilita ao indivíduo-crente e, logo, ao trabalhador-crente pautar a sua conduta no local de trabalho pelas suas crenças religiosas. Significa isto que o trabalhador pode, em regra, manifestar as suas crenças religiosas através da adoção de uma imagem exterior compatível com essas mesmas crenças usando um certo vestuário ou determinados símbolos religiosos. Além disso, a liberdade de religião se pode exercitar tanto através da linguagem oral como através da linguagem universal dos signos, de tal modo que o uso de peças de tipo religioso deve ser garantido pelo direito fundamental da liberdade religiosa.

\section{O PROSELITISMO}

Os comportamentos proselitistas, quando exercidos no local de trabalho, podem pôr em causa a tranquilidade do ambiente laboral e, portanto, ser visto como uma forma de perturbação da normal execução da prestação de trabalho. Mas, por outro lado, qualquer repressão ao comportamento proselitista pode ser considerada uma obstrução à liberdade religiosa. Cabe, portanto, determinar os limites a impor ao trabalhador.

\section{REFERÊNCIAS BIBLIOGRÁFICAS}

ÀLVARO MONTERO, Àngel. "El conflicto de libertades", Actualidad jurídica, Aranzadi, n. ${ }^{\text {o }}$ $813,2011$.

APARICIO TOVAR, Joaquín. "Empresas ideologicas y derechos fundamentales del trabajador", in Autoridad y democracia en la empresa coord. Joaquín Aparicio e Antonio Baylos, Trotta, Madrid, 1992, pp. 77-94 e "Relacion de trabajo y libertad de pensamiento en las empresas ideológicas", in Lecciones de Derecho del trabajo en homenaje a los profesores Bayón Chacón y Del Peso Calvo, Facultad de Derecho, UCM, Madrid, 1980. 
BROWN, Steven. "Leaving the spiritual sphere: religious expression in the public workplace", Journal of Church and State, vol. 49, n. ${ }^{\circ}$ 4, 2007.

CAÑAMARES ARRIBAS, Santiago. "Libertad religiosa y seguridad pública en la experiencia jurídica canadiense", Ius Canonicum, n. ${ }^{\circ}$ 94, 2007.

CASTRO JOVER, María Adoración. "Libertad de conciencia, laicidad y privacidad" in Libertad de conciencia y laicidad en las instituciones y servicios públicos, coord. Dionisio Llamazares Fernández, 2005.

CAYETANO NÚÑEZ GONZÁLEZ, Cayetano. Interculturalidad y Derecho del Trabajo: Una aproximación a la gestión no discriminatoria de la diversidad cultural en la empresa, Tirant lo Blanch, Valencia, 2009.

CORDEIRO, António Menezes. "Da situação jurídica laboral; perspectivas dogmáticas do Direito do trabalho, Revista da Ordem dos Advogados, ano 42, Lisboa, 1982.

FERNANDES, António Monteiro. Direito do Trabalho, 17. a ed., Edições Almedina, Coimbra, 2014.

FORTIER, Vincente. "Le juge et le pluralisme religieux", Cahiers de la Justice, n. 4, 2009.

HAMBLER, Andrew. Religious Expression in the Workplace and the Contested Role of Law (Law and Religion), Routledge, 2014.

JÚNIOR, Aloísio Santos. Liberdade religiosa e contrato de trabalho, Editora Impetus, Niterói, 2013.

LASSERRE, Valérie. “Droit et religion”, Recueil Dalloz, n. 17, 2012.

MACHADO, Jónatas. "A jurisprudência constitucional portuguesa diante das ameaças à liberdade religiosa”, Boletim da Faculdade de Direito, n. ${ }^{\circ}$ 82, Coimbra, 2006.

MACHADO, Jónatas. "Liberdade e igualdade religiosa no local de trabalho - breves apontamentos", Cadernos da Escola Judicial do TRT da $4 .^{a}$ Região, n. ${ }^{\circ}$ 3, 2010. 
MACHADO, Jónatas. Liberdade Religiosa numa Comunidade Constitucional Inclusiva, dos direitos da verdade aos direitos dos cidadãos, Coimbra Editora, Coimbra, 1996, p. 264.

MACHADO, Susana Sousa. A discriminação religiosa na perspetiva das relações laborais, in Contrato de trabalho e liberdade religiosa, Editorial Juruá, Porto, 2018.

MACLURE, Jocelyn / BOUCHER, François. Conclusions generals: Enjeux et perspectives de l'obligations d'accomodement raisonnable dans les sociétés pluralists, E. Bribosia / I. Rorive (coord.), L'accommodement de la diversité religieuse: regards croisés - Canada, Europe, Belgique, Bélgica, Peter Lang, Bruxelas, 2015.

REIS, Raquel Tavares dos. "Direitos, liberdades e garantias da pessoa do trabalhador despedido em razão da sua conduta extra laboral”, Gestão e Desenvolvimento, vol. 10, 2001.

ROJAS RIVERO, Gloria. La libertad de expresión del trabajador, Editorial Trotta, Madrid, 1991.

SAVATIER, Jean. "La situation, au regard du droit du travail, des pasteurs de l'Église réformée", Droit Social, n. ${ }^{\circ}$ 4, 1987.

VALDÉS DAL-RÉ, Fernado. "Libertad religiosa y contrato de trabajo”, in AA. VV., Las transformaciones del derecho del trabajo en el marco de la Constitución Española: Estudios en homenaje al profesor Miguel Rodríguez-Piñero y Bravo-Ferrer, Editorial La Ley, Madrid, 2006.

VICKERS, Lucy. "Religious Freedom: Expressing Religion, Attire, and Public Spaces", Journal of Law and Policy, vol. 22, n. ${ }^{\circ}$ 2, 2014, p. 602, disponível em http://brooklynworks.brooklaw.edu/jlp/vol22/iss2/4.

Trabalho recebido em 04 de outubro de 2019

Aceito em 06 de dezembro de 2020 